\title{
Analysis of Geo Positioning System Using RF \& DA
}

\author{
Jaspreet Kaur Kohli, Amol Potgantwar \\ Department of Computer Engineering, Sandip Foundation Institute of Technology and Research Centre, \\ Nashik, India \\ Email: preets0313@gmail.com, amol.potgantwar@sitrc.org
}

Received 5 March 2016; accepted 24 April 2016; published 27 April 2016

Copyright (C) 2016 by authors and Scientific Research Publishing Inc.

This work is licensed under the Creative Commons Attribution International License (CC BY).

http://creativecommons.org/licenses/by/4.0/

(c) (i) Open Access

\begin{abstract}
Indoor positioning systems (IPSs) have been intended to provide position information of persons and devices. Higher user percentage of handheld devices such as tablets or mobile phones had led to the development of a number of indoor positioning systems. In this research a work on a real time portable RFID indoor positioning device such as on smartphone will be performed. The personal networks will be designed to meet the users' needs and interconnect users' devices equipped with different communications technologies in various places to form one network for better result. Radio frequency identification (RFID) with directional antenna has proved its potential for locating objects in indoor environment. Hence, the proposed device idea will be used to exploit various unknown locations in an indoor environment such as college campus; this interpretation will rely on Wireless LAN, Received Signal Strength values from Access Points (AP) in specific mentioned arenas; these APs will be monitored constantly by RFID with directional antenna (DA) and handheld devices. For obtaining the better results from existing devices, algorithms of Range Estimation are proposed, which can be used on various handheld devices for locating indoor objects.
\end{abstract}

\section{Keywords}

Global Positioning System (GPS), Indoor Positioning System (IPS), Radio Frequency Identification (RFID), Received Signal Strength (RSS), Directional Antenna (DA)

\section{Introduction}

The idea of RFID based navigation in indoor environment is becoming very popular in today's era because of its low cost and less consumption of energy. Moreover, it is even gaining a lot of interests in industry and academics [1]. The wide usage of wireless technologies is an attraction for researchers to develop an application for lo- 
cation tracking in indoor environment and to deploy these systems on handheld devices such as mobile phones, tablets, etc. The idea here is to propose a system for portable devices with Radio Frequency and Directional Antenna to provide flexibility and dynamic solutions for the realistic and small-scale indoor areas such as some organizations (college, industries, etc.). This proposed work of the system will initiate the mobile phone device that connects to the server and accordingly gives the response to the user of their locations and command to take accurate to find the destination.

Indoor positioning system is generally used for locating required objects or places or people in buildings i.e. in either small or large closed environments. Global Positioning System (GPS) [2] is a very commonly used localization system in today's era. GPS is an existing system whose working depends on satellites and its signal. Due to the attenuation of the satellite signals GPS does not work when the respective object is detected in an indoor/closed environment [3]. So, to overcome the disadvantage of working GPS in closed area and locating objects accurately, a varied number of researchers developed indoor positioning systems such as RADAR system which was developed by Microsoft's researcher's laboratory; this system's working is based on Wi-Fi signal strength and location fingerprinting techniques [4]. Another indoor location sensing system developed by AT \& T Cambridge was Active Badges [5]; this developed system used diffuse infrared technology to realize indoor objects or locations. Crickets [6], Active Bats [7] and Dolphin [8] are some more IPS based on ultrasonic positioning systems. The computer vision system [9] and the cell phone positioning system are yet another development of indoor positioning system. The system, Spot ON RFID [10] sensing in the year 2013, consists of RFID tags, RFID readers and the signal communicating between the tags and readers. The foundation of this system is the radio signal strength information from several tags to reader and then uses the classifier algorithm to describe the user's location. The high end terminologies used in the proposed idea are as follows:

\subsection{RFID Technology}

RFID is a tracking technology which is used to authenticate and identify tags that are applied to any object or individuals. Radio Frequency Identification and Detection is a generalized term used for technologies that makes use of radio waves to identify objects and people. The RFID uses power from the reader's signal to reflect this signal back. Some tags contain build in power source and some needs power from external battery. Tags may modulate the signal to send information, such as an ID no. back to the reader. In short, in a typical RFID System, tags are attached to objects to be technology that make use of radio waves to automatically identify individual objects. An RFID system is composed of three main elements as shown in Figure 1.

\subsubsection{RFID Tag}

The proposed idea of the system will be using RFID tag to guide the visitor to their destination. RFID tag will contain information about the user like stag id, visitor id etc. The tag's chip or integrated circuit (IC) delivers performance, memory and extended features to the tag. The chip is pre-programmed with a tag identifier (TID), a unique serial number assigned by the chip manufacturer, and includes a memory bank to store the items' unique tracking identifier (called an electronic product code or EPC). The basic types of tags are Active and Passive tags. Passive tags basically do not contain internal battery. That means passive tags take their operating power from the field generated by the person who reads. Active tags have a transmitter and their internal battery (power).

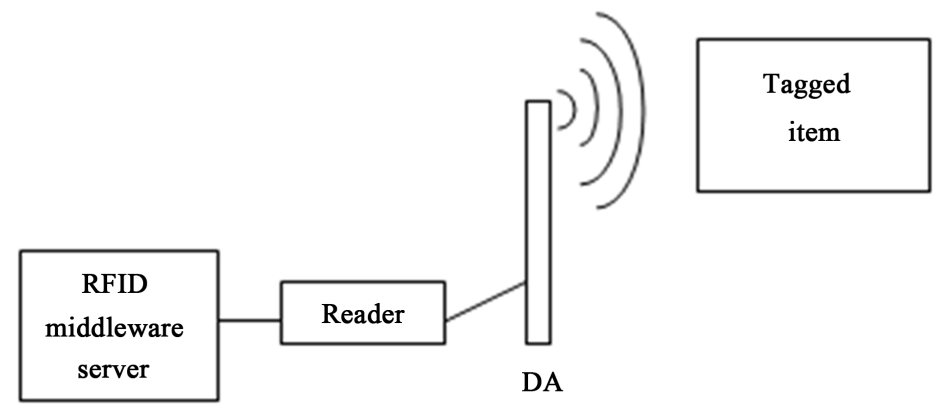

(Directional antenna) 


\subsubsection{RFID Reader}

System uses RFID reader for reading the RFID tags and sends the current location of the visitor to the server. An RFID reader, also known as an interrogator, is a device that provides the connection between the tag data and the server. The reader communicates with tags that are within its field of operation, performing number of tasks such as encoding, filtering etc.

\subsubsection{Directional Antenna}

Directional Antenna is basically used in order to send the tag information of visitor to the server, this information will be transferred wirelessly. Tag antennas collect energy and channel it to the chip to turn it on. Generally, the larger the tag antenna's area, the more energy it will be able to collect and channel toward the tag chip, and the further read range the tag will have.

\subsection{Received Signal Strength}

It is a measurement of the energy that is available in the received radio signal. In many of the existing IPS, based on radio waves uses RSS on a great scale. Received signal strength determines the characteristics and nature of location fingerprinting. The generalized formula used for calculating RSS is as given in the Equation (1).

$$
\text { RSS }=P_{t}-P L\left(d_{0}\right)-10 \alpha \log _{10} \frac{d}{d_{0}}+X_{\sigma R S S}
$$

where,

RSS: Received Signal Strength measured in $\mathrm{dBm}$

Variable $d$ : Distance from the sender to the receiver

$\alpha$ : Path loss component

$P_{t}$ : Transmitted energy of the sender

$P L\left(d_{0}\right)$ : Loss in energy at distance $d_{0}$

$X$ : Random variable representing the noise with variance $\sigma$ RSS

\section{Literature Survey}

Geographical navigation by using various GPS tracking system is become most important part in day to day activity, where people have to visit various unknown locations for various purposes [11]. During these activities wastage of time due to unknown location or unawareness of accurate address may cause delay in meeting etc. [12].

GPS navigation by using current available devices in market is become much more impressive option to avoid various security, misguide in travelling, delay etc. problems [13]. Likewise same problems are being faced by users some sort of big organization such as college, industry or any equivalent places [5] [14] [15]. So to facilitate such activity the new device idea is being proposed which will interact with central server of concerned organization \& visitor's mobile with the help of RFID, DA (Directional Antenna). During navigation various input\& output parameters such as accuracy, scalability, energy consumption, efficiency and division multiple access (GSM/CDMA) mobile cellular network to estimate the location of outdoor mobile clients. However, the accuracy of the method using cell-ID or enhanced observed time difference (E-OTD) is generally low (in the range of 50 $200 \mathrm{~m}$ ), depending on the cell size [16] [17]. Environmental factors have to be monitored for the purpose of performance contribution \& to obtain efficiency \& accuracy of the system [18]. A number of systems have used global system of mobile/code. Table 1 shows various Indoor positioning technologies [5] used.

\section{Proposed System Idea}

For the purpose of avoiding the drawbacks of existing system this paper propose the new system with extended ideas. Proposed system will implement a navigation system for robot application. Here system will use RFID tags for the purpose of giving instructions to the robot. System will load some tag numbers and direction instructions in programmer. When robot system will be started to move, it will detect the path for navigation and start navigation on given path. At some point in given specified area, user has to put RF tag. This tag will be read by RF reader which is placed on robot. Every tag has one unique no. System will scan the number and its instruction for direction. As per direction instruction, robot will change the direction and reach to destination. 
Table 1. Various indoor positioning techniques.

\begin{tabular}{|c|c|c|c|}
\hline Technologies & Advantages & Disadvantages & Accuracy \\
\hline Ultrasound & $\begin{array}{l}\text {-Simple and cheap equipment } \\
\text {-Precision measurement possibilities }\end{array}$ & $\begin{array}{l}\text {-The necessity of the establishment } \\
\text { of the recipients in every room } \\
\text {-Negative influence a high density-tone }\end{array}$ & $\begin{array}{l}\text {-A few centimeters } \\
\text { when it is placed } \\
\text { frequent enough }\end{array}$ \\
\hline RFID & $\begin{array}{l}\text {-The transmitter and receiver } \\
\text { don't need to see each other directly. } \\
\text {-Opportunity to work in all } \\
\text { types of environments } \\
\text {-Fast interactions }\end{array}$ & $\begin{array}{l}\text {-Passive tags have low precision } \\
\text { than active tags. } \\
\text {-RFID Readers are expensive }\end{array}$ & $\begin{array}{l}1 \text { - } 10 \text { meters } \\
\text { (extendable) }\end{array}$ \\
\hline Bluetooth & $\begin{array}{l}\text {-Any kind of Bluetooth device can } \\
\text { be monitored (cell phone, mp3 player etc.) } \\
\text {-Variable reading distance (1 m vicinity) }\end{array}$ & $\begin{array}{l}\text {-Cost effective for large scale installation } \\
\text {-Limited bandwidth } \\
\text {-Transmission delay. } \\
\text {-The possibly of a maximum of seven } \\
\text { sub-links corresponds to main connection }\end{array}$ & 2 - 10 meters \\
\hline $\begin{array}{l}\text { WLAN } \\
\text { (Wi-Fi) }\end{array}$ & $\begin{array}{l}\text {-The possibility of use the } \\
\text { infrastructure of IEEE } 802.11 \\
\text {-Low cost }\end{array}$ & $\begin{array}{l}\text {-Poor performance for multilayered } \\
\text { and very dense areas. } \\
\text {-Due to signal reflection and dynamic } \\
\text { network structure variable signal strength. }\end{array}$ & $\begin{array}{l}1 \text { - } 3 \text { meters } \\
\text { (in range of } 50 \text { meters) }\end{array}$ \\
\hline Infrared & $\begin{array}{l}\text {-Compact } \\
\text {-Low power consumption }\end{array}$ & $\begin{array}{l}\text {-Sensitive to daylight } \\
\text {-Receiver and transmitter needs } \\
\text { to see each other directly }\end{array}$ & 5 - 10 meters \\
\hline
\end{tabular}

Here system requires multiple tags to create random path. Also as per the movement, robot will send its GPS location to machine or personal computer (PC) and it will display position of the RFID tag on it. Here system will give forward, backward, left and right and stop instructions to robot.

\subsection{Segment Identification}

A particular block of signal in terms of time interval will be taken for sampling and analysis purpose. The processed segments further will be transferred to the range estimation block. In this proposed idea the segment will be transferred via directional antenna to RFID middleware connected to the server.

\subsection{Range Estimation}

The proposed range estimation algorithm calculates range of the registered users depending on the scanning of RFID tags on previous reader nodes and the current reader node. Then the location of the user's mobile is calculated by using RSS values and eradicating the angle dependent loss errors. The noise in the signal i.e. the error in the signal will be reduced from it by using Kalman filter technique. After the unwanted part of the signal is cleared the resultant signal will give a better output strength.

\subsection{Angle Dependent Loss Component}

The angle loss within the tracking area is calculated by using the backscattered signals from RFID devices. After identification of the reader's location the angles will be calculated. It is usually calculated from the specific antenna radiation pattern.

\section{Methodology}

The system consist multiple components as shown in the Figure 2. There will be a visitor and an admin who directly interact with the system. Visitors have to register first. After registration visitors get the RFID tags. The tags contain the information about the visitor like visitor id, name, destination, purpose etc. The readers will be installed on each corner of the campus. Visitors need to swap the tag to reader in order to get the direction of destination. As soon as visitor swaps the tag, the RF reader makes contact with the server. Server gets the visitor id, name, destination, tag id and start finding the nearest path to the destination from the current position of the visitor. Then server sends the information of nearest path with direction notification form onto the visitors' mobile device. 
After getting direction visitors can move forward to next reader and swap card, and can get the destination in less time and more accurately.

\section{Experimental Setup}

The implementation of this system will be performed using java jdk1.8 \& Net Beans 8.0 on windows OS with 1 GB RAM \& 500 GB hard disk. Hardware module will be integrated with RS232 cable using comp port. This system access location parameters from all the RF tags. The major hardware components of the system consist of ARM 7 controller, RFID tags, RFID readers interconnected with each other. Hardware Layout is presented in Figure 3.

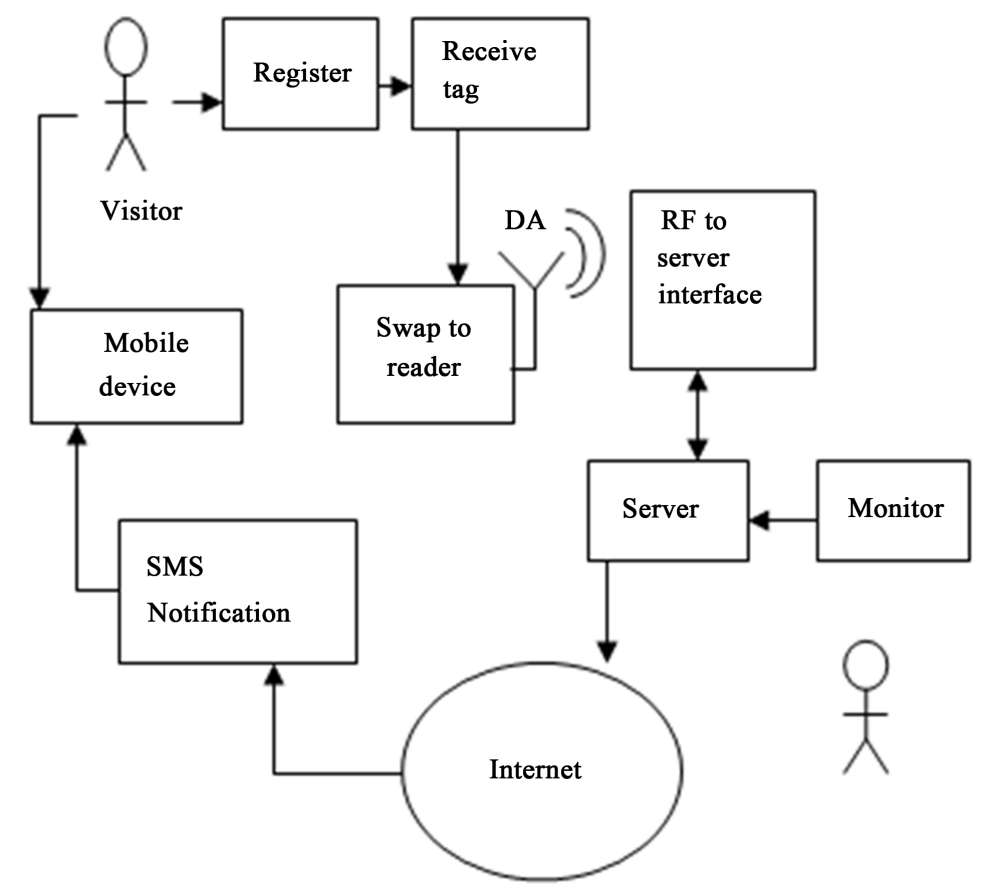

Figure 2. Block diagram of proposed system idea.

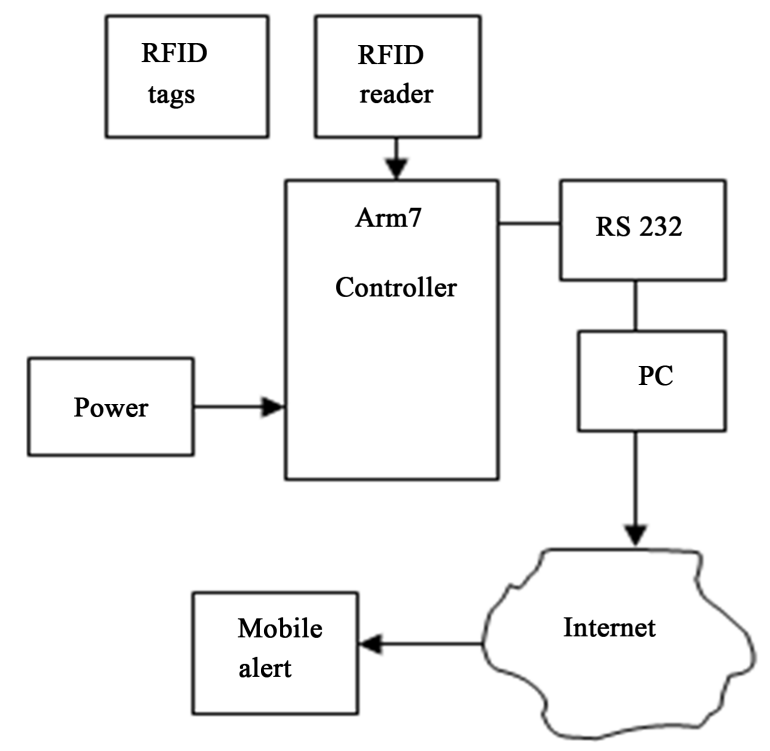

Figure 3. Block diagram of hardware layout. 


\section{Conclusion}

In this implementation the study of effects of real time system with RFID based positioning system is processed. The comparison of various parameters such as signal strength, geographical position \& radiation pattern etc. is performed along with the analysis of various parameters such as accuracy, scalability, precision, delay, etc. A study on RFID based indoor positioning system with directional antenna has been introduced. Usages and performances of various types of readers and tags have been investigated and the best combination has been selected. This idea of proposed system can be merged with many existing systems such as visitor guidance, information kiosk in organization, large and geographically distributed organization, etc. This work can be further expanded to quality and reliability study.

\section{References}

[1] Qiu, R.G. (2007) RFID-Enabled Automation in Support of Factory Integration. Robotics and Computer-Integrated Manufacturing, 23, 677-68. http://dx.doi.org/10.1016/j.rcim.2007.02.002

[2] Department of Defence United States of America and GPS Navstar (2008) Global Positioning System Standard Positioning Service Performance Standards. 4th Edition.

Want, R., Hopper, A., Falcao, V. and Gibbons, J. (1992) The Active Badge Location System. ACM Transactions on Information Systems, 40, 91-102. http://dx.doi.org/10.1145/128756.128759

[3] Garmin Corporation (2001) About GPS. Website. http://www.garmin.com/aboutGPS/

[4] Pathak, O., Palaskar, P., Palkar, R. and Tawari, M. (2014) Wi-Fi Indoor Positioning System Based on RSSI Measurements from Wi-Fi Access Points-A Trilateration Approach. International Journal of Scientific and Engineering Research, 5, 1234-1238.

[5] Want, R., Hopper, A., Falcao, V. and Gibbons, J. (1992) The Active Badge Location System. ACM Transactions on Information System, 40, 91-102. http://dx.doi.org/10.1145/128756.128759

[6] Priyantha, N.B., Chakraborty, A. and Balakrishnan. H. (2000) The Cricket Location-Support System. Proceeding of MOBICOM 2000, Boston, August 2000, 32-43. http://dx.doi.org/10.1145/345910.345917

[7] Harter, A., Hopper, A., Steggles, P., Ward, A. and Webster, P. (1999) The Anatomy of a Contextaware Application. Proceeding of the 5th Annual ACM/IEEE International Conference on Mobile Computing and Networking, Seattle, August 1999, 59-68. http://dx.doi.org/10.1145/313451.313476

[8] Minami, M., Fukuju, Y., Hirasawa, K., Yokoyama, S., Mizumachi, M., Morikawa, H. and Aoyama, T. (2004) Dolphin: A Practical Approach for Implementing a Fully Distributed Indoor Ultrasonic Positioning System. Ubicomp, 347-365. http://dx.doi.org/10.1007/978-3-540-30119-6 21

[9] Krumm, J., Harris, S., Meyers, B., Brumitt, B., Hale, M. and Shafer, S. (2000) Multi Camera Multi-Person Tracking Easy Living. Third IEEE International Workshop on Visual Surveillance, Dublin, 1 July 2000, 1-8. http://dx.doi.org/10.1109/VS.2000.856852

[10] Hightower, J., Want, R. and Borrielo, G. (2000) SpotON: An Indoor 3D Location Sensing Technology Based on RF Signal Strength. Technical Report, University of Washington, Seattle, Wash.

[11] http://www.safecomprogram.gov/NR/rdonlyres/D8BFF5A9-47A7-4496-AB93-611DD043C3E0/0/emerging_wireless_ technologies_enhanced_911.pdf

[12] Lee, C., Chang, Y., Park, G., et al. (2014) Indoor Positioning System Based on Incident Angles of Infrared Emitters. Proceedings of the 30th Annual Conference of IEEE Industrial Electronics Society (IEOCON'04), 3, 2218-2222.

[13] Rodriguez, M., Pece, J. and Escudero, C. (2005) In-Building Location Using Bluetooth. International Workshop on Wireless Ad-Hoc Networks.

[14] Dong, Z., Wu, Y. and Sum, D. (2013) Data Fusion of the Real-Time Positioning System Based on RSSI and TOF. 5th International Conference on Intelligent Human-Machine Systems and Cybernetics, 2, 503-506. http://dx.doi.org/10.1109/ihmsc.2013.267

[15] Torteeka, P., Xiu, C. and Yang, D.K. (2014) Hybrid Technique for Indoor Positioning System Based on Wi-Fi Received Signal Strength Indication. 2014 International Conference on Indoor Positioning and Indoor Navigation (IPIN), Busan, 27-30 October 2014, 48-57.

[16] Ni, L.M., Liu, Y., Lau, Y.C. and Patil, A.P. (2003) LANDMARC: Indoor Location Sensing Using Active RFID. Proceedings of the 1st IEEE International Conference on Pervasive Computing and Communications (PerCom'03), Fort Worth, 23-26 March 2003, 407-415. 
[17] UbiSense Company. http://www.ubisense.net

[18] Aitenbichler, E. and Muhlhauser, M. (2003) An IR Local Positioning System for Smart Items and Devices. Proceedings of the 23rd International Conference on Distributed Computing Systems Workshops, Providence, 19-22 May 2003, 334-339. http://dx.doi.org/10.1109/icdcsw.2003.1203576 